\title{
Influence of Life Style Factors on the Lipid Profile in Middle-Aged Healthy Female Subjects (30-50 Years)
}

\author{
Uma IYer, ${ }^{*}$ Kavita Sharma, Shilpa Deshmukh, \\ Karishma FERnANDES, and Uliyar MANI \\ Department of Foods and Nutrition, Faculty of Home Science, \\ M.S. University of Baroda, Vadodara 390 002, India
}

(Received February 23, 2000)

Summary The atherogenic process is influenced by the levels of different plasma lipoproteins, and epidemiological studies have shown a positive relationship between increased levels of serum total cholesterol and coronary heart disease (CHD). Thus, it becomes essential to establish normal levels of serum lipids for the respective range of population, for the normal level of one group cannot be accepted for that of another. Moreover, lipid ranges for the various age groups of Indians are scanty. Hence, the present investigation was undertaken to study the lipid levels in the middle-aged female population of urban Baroda and the influence of life style factors on them. One hundred and twenty-five middle-aged female subjects (30-50 years) were enrolled from the five administrative wards of Baroda. Their background, clinical, and dietary information were collected through a structured questionnaire. Fasting venous blood samples were drawn, and the serum was used for analysis of fasting blood sugar and lipid profile. The results showed that the mean total cholesterol (TC), high-density lipoprotein cholesterol (HDL-C), low-density lipoprotein cholesterol (LDL-C), and very-low-density lipoprotein cholesterol (VLDL-C) were $177 \mathrm{mg} / \mathrm{dl}, 46 \mathrm{mg} / \mathrm{dl}, 98 \mathrm{mg} / \mathrm{dl}$, and $31 \mathrm{mg} / \mathrm{dl}$, respectively. The dietary data indicated that the mean caloric intake of the subjects was $1,464 \mathrm{kcal}$ ( $78 \%$ of Recommended Dietary Allowances (RDA) for Indians), with fat intake being twice the amount of RDA ( $\geq 60 \mathrm{~g}$ fat/day). Also, when the lipid profile of the subjects was studied in relation to the type of diet consumed, we found that those consuming non-vegetarian foods had non-significantly higher TC and triglyceride (TG) levels compared with vegetarians. The prevalence of obesity based on body mass index (BMI) $\geq 25$ was $39 \%$, and that based on the waist/hip ratio (WHR) $\geq 0.85$ was $15 \%$. This indicates a high prevalence of general and central obesity in these middle-aged female subjects. Daily exercise

\footnotetext{
*To whom correspondence should be addressed.
} 
had a positive impact on lipid profile, as indicated by an increase in the HDL-C, which has a cardioprotective function.

Key Words: life style factors, lipoprotein levels, total cholesterol

Coronary heart disease (CHD) is a syndrome arising from failure of the coronary arteries to supply sufficient blood to the myocardium. CHD and stroke are the two major manifestations of cardiovascular disease (CVD) which is a collective name for a number of diseases affecting the supply of blood to the heart. CHD is also known as ischemic heart disease (IHD), and its most common forms are myocardial infarction (heart attack) and angina pectoris (chest pain).

Numerous epidemiological studies have shown that lipid and lipoprotein levels are predictive for CHD [1]. The incidence of CHD is related positively to the level of low-density lipoprotein cholesterol (LDL-C) and negatively to that of high-density lipoprotein cholesterol (HDL-C) [2], and $\mathrm{TC} / \mathrm{H}$ and $\mathrm{L} / \mathrm{H}$ is more predictive of CHD than is either LDL-C or total cholesterol (TC) [3]. Thus, serum lipid levels play an important role in the prediction of risk for CHD.

In addition various studies have also shown that serum lipid values vary among the two genders; and though coronary artery disease (CAD) is often viewed as a male affliction, women are not immune to it [4]. Also, it is known that CAD is not due to any single factor but due to several factors, which are called 'risk factors.' Several known risk factors of CAD include personal characteristics on which one can have no control, e.g., age, sex, and family history. Learned forms of behavior, which can be intervened and changed, are stress, cigarette smoking, sedentary life style, obesity, food habits (excess fat, excess sugar, and excess salt). Lastly, background conditions, which can be screened and then treated, include diseases such as hypertension, diabetes mellitus, and hyperlipidemia.

From the literature available there are few conclusions which can be drawn and these include:

a) Normal levels of one age group, gender or population cannot be accepted as being normal levels.

b) The risk factors are interactive not only additively but also multiplicatively when they are present simultaneously.

c) The risk factors are not specific for CHD but are involved in the natural history of several diseases.

d) Risk factors synergistically influence lipid levels, and so it is also necessary to observe the influence of these factors on lipid levels.

All of the above conclusions indicate that norms set for Western populations may not be applicable for the Indian setting in view of the divergent dietary, sociocultural, and life style factors. Moreover, there are no clear-cut norms available for the Indian population; and hence it becomes prudent to establish normative data for each community. With this concept in mind, the present study was 
undertaken to study the lipid profile in middle-aged (30-50 years) female subjects of urban Baroda, India.

\section{MATERIALS AND METHODS}

One hundred and twenty-five female subjects from the living population of urban Baroda were enrolled in the study. Subjects having normal blood pressure, a willingness to cooperate, and no apparent complications were selected. Information regarding the family history, education level, occupation, socioeconomic status, exercise profile, age at menopause, number of children, etc. were collected by using a structured questionnaire. Anthropometric measurements including height, weight, and waist/hip ratio (WHR) of the subjects were recorded by standard procedures. The dietary profile of the subjects was taken by the 24-h dietary recall method, and the nutritive values of the foods consumed were calculated from the values given in the 'Nutritive Value of Indian Foods' by Gopalan et al. [5]. For the estimation of various biochemical parameters, an overnight fasting $(12 \mathrm{~h}$ ) blood sample was collected; and serum was analyzed for various parameters including fasting blood sugar (FBS), triglycerides (TG), total cholesterol (TC), HDL-C, and LDL-C. The analysis of all these parameters was done with enzymatic kits supplied by Glaxo India Ltd., Munibai, India [6-10]. Very-low-density lipoprotein cholesterol (VLDL-C) was calculated by subtracting the sum of HDL-C and LDL-C from TC. The data were then analyzed by using a statistical package for social sciences (SPSS/PC + Version 4.0). Frequency distribution and percentages were calculated along with mean and standard deviation. Unpaired ' $t$-test' was done to test the difference between the mean of the groups. All tests were considered significant at $p<0.05$.

\section{RESULTS}

The clinical profile of the subjects revealed that the average age of the 125 female subjects was 38 years. The mean height and weight of the subjects were $1.55 \mathrm{~m}$ and $57.9 \mathrm{~kg}$, respectively, with the average body mass index (BMI) and WHR being 23.9 and 0.79 , respectively. Table 1 gives the lipid profile of the subjects. The mean values for TC and TG were found to be $177 \mathrm{mg} / \mathrm{dl}$ and $102 \mathrm{mg} / \mathrm{dl}$, respectively. Being atherogenic indices of the subjects, $\mathrm{L} / \mathrm{H}, \mathrm{TC} / \mathrm{L}$, and $\mathrm{TC} / \mathrm{H}$ ratios were $2.26,1.87$, and 4.09 , respectively.

Age-wise analysis of the lipid profile of the female subjects $(30-40$ years vs. 40-50 years) revealed interesting trends. The TC and LDL-C levels increased significantly with age in female subjects. With regard to TG no such trend was noticed. The $\mathrm{L} / \mathrm{H}$ ratio was significantly higher in female subjcts in the $40-50$-year age group as compared with that of their younger counterparts $(2.11 \pm 0.96$ vs. $2.51 \pm 1.22, p<0.05$ ).

When percentile values for various lipid parameters were calculated, based on Vol. 28, No. 2, 2000 
the National Cholesterol Education Program expert panel, we obtained the values shown in Table 2.

Table 3 gives the nutrient intake of the subjects. The mean caloric intake of the female subjects was $1,464 \mathrm{kcal}$, with carbohydrates providing $60.2 \%$, proteins, $12.4 \%$, and fats, $27.4 \%$ of the total calories. The intake of antioxidant vitamins, namely, beta carotene and vitamin $\mathrm{C}$, was adequate. The iron intake was $12 \mathrm{mg} /$ day, whereas the calcium intake was $700 \mathrm{mg} /$ day. These results are in line with most of the studies conducted in India [11]. However, the intake of iron was lower than the recommended dietary allowances for Indians, as suggested by the Indian Council of Medical Research [12].

Since fat intake is known to influence the lipid parameters, the data were analyzed looking into the fat intake which is presented in Table 4. As can be seen, the TG value was significantly elevated for subjects consuming more than $60 \mathrm{~g}$ fat/ day compared with that for those subjects consuming less than $60 \mathrm{~g}$. Thus, the consumption of more than twice the amount of Recommended Dietary Allow-

Table 1. Lipid profile of middle-aged female subjects.

\begin{tabular}{lc}
\hline Variable & Value \\
\hline Number of subjects & 125 \\
FBS & $73 \pm 11$ \\
TC & $177 \pm 35$ \\
HDL-C & $46 \pm 11$ \\
LDL-C & $98 \pm 33$ \\
VLDL-C & $31 \pm 30$ \\
TG & $102 \pm 52$ \\
L/H & $2.26 \pm 1.80$ \\
TC/L & $1.87 \pm 0.54$ \\
TC/H & $4.09 \pm 1.48$ \\
\hline
\end{tabular}

Values are expressed as mean $\pm \mathrm{SD}, \mathrm{mg} / \mathrm{dl}$.

Table 2. Quartile values of lipid profile in middle-aged female subjects.

\begin{tabular}{lccc}
\hline Variable & $\begin{array}{c}\text { Below } \begin{array}{c}50 \text { th percentile } \\
\text { Desirable }\end{array} \\
\text { TC }\end{array}$ & $\begin{array}{c}50-75 \text { th percentile } \\
\text { Borderline }\end{array}$ & $\begin{array}{c}\text { 75th percentile } \\
\text { High level }\end{array}$ \\
\hline HDL-C* & $\leq 175$ & $175-196$ & $>196$ \\
LDL-C & $\leq 45$ & $39-45$ & $<39$ \\
VLDL-C & $\leq 27$ & $99-118$ & $>118$ \\
TG & $\leq 90$ & $27-45$ & $>45$ \\
L/H & 2.19 & $90-127$ & $>127$ \\
TC/L & 1.76 & $2.19-3.05$ & $>3.05$ \\
TC/H & 3.88 & $1.76-1.66$ & $>1.66$ \\
\hline
\end{tabular}

Values are expressed as mean $\pm \mathrm{SD}, \mathrm{mg} / \mathrm{dl}$. ${ }^{*}$ Desirable, $\geq 50$ th percentile; Borderline, $25-$ $<50$ th percentile; Low level, $<25$ th percentile. 
ances (RDA) of fat had an adverse effect on the TG level in the female subjects.

Table 5 depicts the lipid profile of the female subjects in relation to the type of diet. When the lipid profile of vegetarians and non-vegetarians was compared, there was a significant difference in HDL-C levels; i.e., the non-vegetarians had higher HDL-C levels than the vegetarians $(53 \mathrm{mg} / \mathrm{dl}$ vs. $45 \mathrm{mg} / \mathrm{dl}, p<0.01$ ), and this had a direct influence in reducing the $\mathrm{L} / \mathrm{H}$ ratio of the non-vegetarians.

The prevalence of obesity based on $\mathrm{BMI} \geq 25$ or WHR $\geq 0.85$, which are the cut-off points suggested by the World Health Organization (WHO), was 39\% or $15 \%$, respectively. When the data were analyzed by taking into consideration both of the parameters together, prevalence of obesity came down to $5.6 \%$.

Lipid profile of the female subjects in relation to BMI indicated that, with an increase in BMI, there was a non-significant increase in TC and LDL-C levels,

Table 3. Nutrient intake of middle-aged female subjects.

\begin{tabular}{lc}
\hline Nutrients & \\
\hline Calories (kcal) & $1,464 \pm 323$ \\
Carbohydrates $(\mathrm{g})$ & $219 \pm 52$ \\
Protein $(\mathrm{g})$ & $45 \pm 13$ \\
Fat $(\mathrm{g})$ & $44 \pm 15$ \\
Total unsaturated fats $(\mathrm{g})$ & $17 \pm 12$ \\
Total saturated fats $(\mathrm{g})$ & $28 \pm 15$ \\
Crude fiber $(\mathrm{g})$ & $8 \pm 2$ \\
Vitamin C (mg) & $117 \pm 79$ \\
Beta carotene $(\mu \mathrm{g})$ & $2,290 \pm 2,271$ \\
Calcium (mg) & $753 \pm 270$ \\
Iron (mg) & $12 \pm 5$ \\
\% Calories & \\
$\quad$ Carbohydrates & 60.1 \\
Protein & 12.4 \\
$\quad$ Fat & 27.4 \\
$\quad$ Unsaturated fats & 10.3 \\
\hline
\end{tabular}

Values are expressed as mean $\pm \mathrm{SD}, \%$.

Table 4. Lipid profile of middle-aged female subjects in relation to fat intake.

\begin{tabular}{|c|c|c|c|c|c|c|}
\hline \multirow[b]{2}{*}{ Variable } & \multicolumn{3}{|c|}{ Fat intake } & \multicolumn{3}{|c|}{ ' $t$ ' Values } \\
\hline & $\begin{array}{c}\leq 30 \mathrm{~g} \\
(N=20)\end{array}$ & $\begin{array}{c}30.01-60 \mathrm{~g} \\
(N=87)\end{array}$ & $\begin{array}{c}>60 \mathrm{~g} \\
(N=18)\end{array}$ & $\begin{array}{c}\leq 30 \text { vs. } \\
30.01-60 \mathrm{~g}\end{array}$ & $\begin{array}{l}\leq 30 \text { vs. } \\
>60 \mathrm{~g}\end{array}$ & $\begin{array}{c}30.01-60 \mathrm{vs} \\
>60 \mathrm{~g}\end{array}$ \\
\hline TC & $173 \pm 36$ & $177 \pm 35$ & $184 \pm 35$ & 0.50 & 0.99 & 0.78 \\
\hline HDL-C & $43 \pm 11$ & $47 \pm 12$ & $43 \pm 9$ & 1.42 & 0.09 & 1.48 \\
\hline LDL-C & $100 \pm 37$ & $98 \pm 30$ & $95 \pm 44$ & 0.30 & 0.40 & 0.35 \\
\hline VLDL-C & $29 \pm 19$ & $31 \pm 23$ & $31 \pm 19$ & 0.41 & 0.29 & 0.08 \\
\hline $\mathrm{TG}$ & $99 \pm 57$ & $99 \pm 45$ & $128 \pm 72$ & 0.08 & 1.39 & $2.32 * *$ \\
\hline
\end{tabular}

Values are expressed as mean \pm SD. ${ }^{* *}$ Significantly different at $p<0.01$.

Vol. 28, No. 2, 2000 
whereas HDL-C levels tended to fall. The TC/L ratio was significantly lower, and $\mathrm{TC} / \mathrm{H}$ ratio was significantly increased, in female subjects with higher BMI (Table $6)$.

The lipid profile of the female subjects having different levels of WHR is given in Table 7. The data indicates that there was a significant decrease in HDL-C with an increase in WHR, which had a direct influence in increasing the TC/H ratio. A significant increase in the TG level with an increase in WHR was also observed. In Table 8 it can be seen clearly that lipid parameters of subjects having a BMI $\geq$ 25 at different levels of WHR remained unaltered. However, an important observation was that significantly lower levels of HDL-C (which is an important cardioprotective factor) were seen as WHR increased.

The impact of exercise on lipid parameters was also assessed (Table 9). When the lipid profile of those subjects doing exercise was compared with that of those not doing exercise, both BMI and TG values were significantly higher in the former group. These subjects exercised because they knew that they were overweight. Also, slightly lower values for HDL-C were observed in subjects not doing exercise than

Table 5. Lipid profile of middle-aged female subjects in relation to the type of diet.

\begin{tabular}{lccl}
\hline Variable & $\begin{array}{c}\text { Vegetarians } \\
(N=80)\end{array}$ & $\begin{array}{c}\text { Non-vegetarians } \\
(N=22)\end{array}$ & ' $t$ ' Value \\
\hline TC & $178 \pm 37$ & $183 \pm 32$ & 0.64 \\
HDL-C & $45 \pm 10$ & $53 \pm 11$ & $3.07^{* *}$ \\
LDL-C & $98 \pm 34$ & $99 \pm 24$ & 0.1 \\
VLDL-C & $31 \pm 20$ & $32 \pm 26$ & 0.05 \\
TG & $99 \pm 53$ & $119 \pm 55$ & 1.55 \\
L/H & $2.31 \pm 1.07$ & $1.92 \pm 0.44$ & 1.86 \\
TC/L & $1.88 \pm 0.55$ & $1.92 \pm 0.40$ & 0.18 \\
TC/H & $4.18 \pm 1.52$ & $3.59 \pm 0.92$ & 1.74 \\
\hline
\end{tabular}

Values are expressed as mean $\pm \mathrm{SD}, \mathrm{mg} / \mathrm{dl}$. ${ }^{* *}$ Significantly different at $p<0.01$.

Table 6. Lipid profile of middle-aged female subjects based on BMI.

\begin{tabular}{lccccccc}
\hline & \multicolumn{3}{c}{ BMI } & & \multicolumn{3}{c}{ ' $t$ ' Values } \\
\cline { 2 - 5 } \cline { 7 - 8 } Variable & $18-22.0$ & $22.01-24.9$ & $\geq 25$ & & $18-22.0$ vs. & $18-22.0$ vs. & $22.01-24.9$ vs. \\
& $(N=44)$ & $(N=29)$ & $(N=49)$ & & $\geq 25$ & $22.01-24.9$ & $\geq 25$ \\
\hline TC & $170 \pm 38$ & $177 \pm 28$ & $182 \pm 36$ & & 1.48 & 0.77 & 0.65 \\
HDL-C & $48 \pm 10$ & $46 \pm 12$ & $45 \pm 12$ & & 1.66 & 0.71 & 0.49 \\
LDL-C & $93 \pm 33$ & $97 \pm 30$ & $102 \pm 36$ & & 1.32 & 0.58 & 0.64 \\
VLDL-C & $30 \pm 22$ & $34 \pm 17$ & $29 \pm 23$ & & 0.19 & 0.82 & 0.96 \\
TG & $84 \pm 44$ & $101 \pm 49$ & $122 \pm 54$ & & $3.67^{* * *}$ & 1.48 & 1.76 \\
L/H & $2.00 \pm 0.89$ & $2.32 \pm 1.23$ & $2.44 \pm 1.13$ & & $2.03^{*}$ & 1.26 & 0.44 \\
TC/L & $1.96 \pm 0.49$ & $1.98 \pm 0.63$ & $1.71 \pm 0.5$ & & $2.35^{*}$ & 0.14 & $2.08^{*}$ \\
TC/H & $3.69 \pm 1.24$ & $4.17 \pm 1.72$ & $4.35 \pm 1.47$ & & $2.30^{*}$ & 1.37 & 0.49 \\
\hline
\end{tabular}

Values are expressed as mean $\pm \mathrm{SD}, \mathrm{mg} / \mathrm{dl}$. ${ }^{*}$ Significantly different at $p<0.05 .{ }^{* * *}$ Significantly different at $p<0.001$. 
Table 7. Lipid profile of middle-aged female subjects based on WHR.

\begin{tabular}{|c|c|c|c|c|c|c|}
\hline \multirow[b]{2}{*}{ Variable } & \multicolumn{3}{|c|}{ WHR } & \multicolumn{3}{|c|}{ ' $t$ ' Values } \\
\hline & $\begin{array}{c}\leq 0.8 \\
(N=78)\end{array}$ & $\begin{array}{c}0.81-0.85 \\
(N=28)\end{array}$ & $\begin{array}{c}\geq 0.86 \\
(N=19)\end{array}$ & $\begin{array}{c}\leq 0.8 \text { vs. } \\
0.81-0.85\end{array}$ & $\begin{array}{c}\leq 0.8 \text { vs } \\
\geq 0.86\end{array}$ & $\begin{array}{c}0.81-0.85 \text { vs. } \\
\quad \geq 0.86\end{array}$ \\
\hline TC & $177 \pm 33$ & $180 \pm 40$ & $176 \pm 37$ & 0.41 & 0.08 & 0.34 \\
\hline HDL-C & $47 \pm 10$ & $46 \pm 13$ & $41 \pm 11$ & 0.39 & $2.47^{*}$ & 1.50 \\
\hline LDL-C & $99 \pm 30$ & $100 \pm 33$ & $97 \pm 31$ & 0.13 & 0.34 & 0.37 \\
\hline VLDL-C & $30 \pm 22$ & $33 \pm 24$ & $34 \pm 19$ & 0.51 & 0.67 & 0.19 \\
\hline TG & $96 \pm 49$ & $108 \pm 56$ & $121 \pm 55$ & 1.07 & $2.01^{*}$ & 0.83 \\
\hline $\mathrm{L} / \mathrm{H}$ & $2.22 \pm 0.98$ & $2.33 \pm 1.16$ & $2.55 \pm 1.15$ & 0.50 & 1.24 & 0.62 \\
\hline $\mathrm{TC} / \mathrm{L}$ & $1.87 \pm 0.43$ & $1.93 \pm 0.59$ & $1.94 \pm 0.56$ & 0.50 & 0.54 & 0.07 \\
\hline $\mathrm{TC} / \mathrm{H}$ & $3.92 \pm 1.26$ & $4.20 \pm 1.76$ & $4.64 \pm 1.79$ & 0.90 & $2.05^{*}$ & 0.84 \\
\hline
\end{tabular}

Values are expressed as mean $\pm \mathrm{SD}, \mathrm{mg} / \mathrm{dl} .{ }^{*}$ Significantly different at $p<0.05$.

Table 8. Lipid profile of middle-aged female subjects based on BMI and WHR.

\begin{tabular}{lcccccccc}
\hline & \multicolumn{3}{c}{ BMI $\geq 25$} & & \multicolumn{3}{c}{ ' $t$ ' Values } \\
\cline { 2 - 3 } \cline { 7 - 9 } Variable & WHR $\leq 0.8$ & WHR $0.81-0.85$ & WHR $\geq 0.86$ & & $\leq 0.8$ vs. & $\leq 0.8$ vs. & $0.81-0.85$ vs. \\
& $(N=29)$ & $(N=13)$ & $(N=7)$ & & $0.81-0.85$ & & $\geq 0.86$ & $\geq 0.86$ \\
\hline TC & $183 \pm 30$ & $178 \pm 49$ & $186 \pm 39$ & & 0.37 & 0.20 & 0.34 \\
HDL-C & $47 \pm 12$ & $42 \pm 11$ & $37 \pm 8$ & & 1.33 & & $2.04^{*}$ & 1.01 \\
LDL-C & $108 \pm 33$ & $98 \pm 34$ & $84 \pm 47$ & & 0.94 & & 1.62 & 0.78 \\
VLDL-C & $24 \pm 21$ & $38 \pm 28$ & $34 \pm 23$ & & 1.81 & & 1.14 & 0.30 \\
TG & $116 \pm 49$ & $135 \pm 66$ & $127 \pm 52$ & & 1.04 & & 0.56 & 0.25 \\
\hline
\end{tabular}

Values are expressed as mean $\pm \mathrm{SD}, \mathrm{mg} / \mathrm{dl} .{ }^{*}$ Significantly different at $p<0.05$.

Table 9. Lipid profile of middle-aged female subjects in relation to exercise.

\begin{tabular}{lccc}
\hline \multirow{2}{*}{ Variable } & \multicolumn{2}{c}{ Exercise } & \multirow{2}{*}{$t$ ' Value } \\
\cline { 2 - 3 } & $+(N=35)$ & $-(N=50)$ & 0.51 \\
TC & $177 \pm 36$ & $180 \pm 33$ & 1.30 \\
HDL-C & $48 \pm 11$ & $45 \pm 11$ & 0.69 \\
LDL-C & $100 \pm 31$ & $105 \pm 32$ & 1.04 \\
VLDL-C & $26 \pm 16$ & $31 \pm 22$ & $3.11^{* *}$ \\
TG & $119 \pm 62$ & $85 \pm 40$ & 1.20 \\
L/H & $2.19 \pm 0.95$ & $2.46 \pm 1.03$ & 0.14 \\
TC/L & $1.85 \pm 0.36$ & $1.83 \pm 0.49$ & 1.16 \\
TC/H & $3.88 \pm 1.40$ & $4.24 \pm 1.39$ & $2.81^{* *}$ \\
BMI & $25.6 \pm 3.67$ & $23.0 \pm 4.50$ & 1.15 \\
WHR & $0.80 \pm 0.05$ & $0.78 \pm 0.05$ & 0.49 \\
Fat intake & $45 \pm 17$ & $43 \pm 14$ & \\
\hline
\end{tabular}

Values are expressed as mean $\pm \mathrm{SD}, \mathrm{mg} / \mathrm{dl}$. ${ }^{*}$ Significantly different at $p<0.01$.

in those doing regular exercise $(45 \mathrm{mg} / \mathrm{dl}$ vs. $48 \mathrm{mg} / \mathrm{dl})$. However, this difference was not statistically significant. 


\section{DISCUSSION}

There is evidence that CHD is more strongly related to the distribution of serum cholesterol among the different lipoprotein classes than to serum TC alone. An increase in serum LDL-C is associated with an increased risk of atherosclerosis, whereas increased HDL-C levels in serum are associated with a decreased risk of the disease. Low levels of HDL-C are indicative of reduced efflux of cholesterol from the arterial wall, thus favoring atherosclerosis. Further, the Framingham data and observations from other population studies have shown HDL-C and the L/H ratio to be more predictive of CHD than TC or LDL-C alone.

In the present study the mean $\mathrm{TC}$ and $\mathrm{TG}$ values of the subjects were found to be $177 \mathrm{mg} / \mathrm{dl}$ and $102 \mathrm{mg} / \mathrm{dl}$, respectively. As can be seen from Table 10, the TC and TG values found in the present study are relatively lower than that reported for the Western population, for both age groups, 30-40 years and 41-50 years. Cholesterol was higher in the Western population, and TG was higher in the presently studied Indian population. The VLDL-C concentration, which may be used as an indication of high TG, was found to be higher in Indian population. LDL-C, which is directly related to TC, was higher in the Western population. The HDL-C level was also found to be higher in the Western population than in the presently studied one. The present data are in line with the studies conducted by Gandhi [13], Mani et al. [14], and Chaddha et al. [15], as given in Table 10.

In the present study, lipid analysis between the vegetarians and nonvegetarians showed a significant difference in HDL-C levels; i.e., it was higher in the non-vegetarians. The reason for this difference could be that $81 \%$ of the non-vegetarians were fish eaters, whose frequency of consuming fish varied from daily to once a week. Studies have indicated that ingestion of fat from marine sources was associated with a reduced incidence of CAD, probably by raising HDL-C levels. In the Zutphen study [16], which was part of a seven country study,

Table 10. Comparison of Indian, Western, and the present study for lipid values in middle-aged female subjects.

\begin{tabular}{lcccccc}
\hline Studies & Age (years) & TC & HDL-C & LDL-C & VLDL-C & TG \\
\hline Western* & $30-40$ & $203 \pm 37$ & $58 \pm 13$ & $111 \pm 31$ & $14 \pm 10$ & $67 \pm 48$ \\
Indian & & & & & & \\
$\quad$ Gandhi (1982) & $30-40$ & $161 \pm 20$ & $37 \pm 8$ & $97 \pm 23$ & $27 \pm 10$ & $139 \pm 18$ \\
$\quad$ Chaddha et al. (1997) & $35-44$ & $203 \pm 40$ & $57 \pm 13$ & $114 \pm 37$ & - & $142 \pm 26$ \\
$\quad$ Present study (1999) & $30-40$ & $170 \pm 34$ & $46 \pm 11$ & $91 \pm 32$ & $31 \pm 20$ & $97 \pm 53$ \\
Western* & $41-50$ & $217 \pm 35$ & $62 \pm 14$ & $130 \pm 24$ & $14 \pm 9$ & $80 \pm 42$ \\
Indian & & & & & & \\
$\quad$ Gandhi (1982) & $41-50$ & $162 \pm 26$ & $37 \pm 11$ & $116 \pm 21$ & $28 \pm 11$ & $143 \pm 28$ \\
$\quad$ Chaddha et al. (1997) & $45-50$ & $215 \pm 47$ & $57 \pm 14$ & $120 \pm 43$ & - & $155 \pm 34$ \\
$\quad$ Present study (1999) & $41-50$ & $189 \pm 34$ & $47 \pm 12$ & $108 \pm 33$ & $30 \pm 25$ & $111 \pm 48$ \\
$\quad$ Mani et al. (1986) & $30-65$ & $184 \pm 24$ & $55 \pm 8$ & $107 \pm 18$ & $20 \pm 11$ & $94 \pm 36$ \\
\hline
\end{tabular}

Values are expressed as mean $\pm \mathrm{SD}, \mathrm{mg} / \mathrm{dl}$. ${ }^{*}$ Cited from study by Gandhi (1982). 
fish consumption was found to be an independent protective factor for CHD, even at a low habitual fish intake equivalent to one or two servings of fish per week ( 30 $\mathrm{g} /$ day).

Another reason for an increase in HDL-C in the case of non-vegetarians could be that $72 \%$ of the non-vegetarians exercised. There is a definite positive correlation between physical activity and increased HDL-C levels [17-21]. Thus, the combined effect of fish consumption and exercise could have had a favorable effect in raising the HDL-C in the non-vegetarians.

In recent days as the standard of living continues to rise, weight gain and obesity are posing a growing threat to the health of inhabitants of countries worldwide. The WHO has recognized obesity as a disease which is prevalent in both developing and developed countries and as the most significant contributor to ill health. In the present study, as per WHO classification of obesity, $39 \%$ of the females were found to be overweight (i.e., BMI $\geq 25$ ) and $15 \%$ of the females had WHR $\geq 0.85$, indicating abdominal obesity. When the lipid profile of the subjects was examined in relation to BMI and WHR, we found that HDL-C levels were low and TG levels were high in overweight and obese subjects. These findings are similar to those observed by Lavie et al. [22]. Studies have also shown WHR to be consistently related to adverse levels of TG and HDL-C [23-27]. In contrast, levels of TC are less strongly associated with body fat distribution $[25,28]$.

With regard to exercise, an interesting observation made in this study was that those women who exercised regularly had a higher BMI and because of this fact they exercised. As most of these subjects had started exercise just 2-3 months prior to the study, no appreciable changes were seen in TC, LDL-C, and VLDL-C levels; but significant differences were seen in HDL-C levels. Similar results were obtained by a number of other investigators [22, 23, 29]. However, the TG values were found to be higher in subjects doing exercise vs. those not doing exercise, which may be attributed to high BMI in the former subjects.

From the present study we conclude that the lipid profile values of the middle-aged female population studied were different from those of a previously studied Western population and that they changed with age, total fat intake, type of diet (i.e., vegetarian vs. non-vegetarian), exercise, BMI, and WHR. Also, keeping the 75th percentile values as cut-off limits for lipid profile and atherogenic indices it can be possible to screen adult female subjects with abnormal lipid profile and help to identify individuals who have higher than desirable values, i.e., 50th percentile values.

\section{REFERENCES}

1. Kannel, W.B., Castelli, W.P., Gordon, T., and Mc Namara, P.M. (1971): Serum cholesterol, lipoproteins and risk of coronary heart disease. The Framingham Study. Ann. Intern. Med., 74, $1-2$.

2. Gordon, T., Castelli, W.P., Hjortland, M.C., Kannel, W.B., and Dawber, T.R. (1977): High

Vol. 28, No. 2, 2000 
density lipoprotein as a protective factor against coronary heart diseases. The Framingham Study. Am. J. Med., 62, 707-714.

3. Lavie, C.J., Ray, S.W., and Gau, G.T. (1987): Prevention of cardiovascular disease. Cardiovasc. Dis., 81, 52-71.

4. Leaf, D.A. (1990): Women and coronary artery disease. Postgrad. Med., 87, 55-59.

5. Gopalan, C., Rama Sastri, B.V., and Balasubranium, S.C. (1994): Nutritive Value of Indian Foods, revised and updated by Narsingarao, B.S., Deosthale, Y.G., and Pant, K.G., National Institute of Nutrition, Hyderabad.

6. Raabo, E. (1969): Methods of enzymatic analysis by GOD/POD method. Scand. J. Clin. Lab. Invest., 12, 402.

7. Mc Gowan, M.W., Artiss, J.D., Standberg, D.R., and Zak, B.A. (1983): Peroxidase coupled method for the colorimetric determination of triglyceride. Clin. Chem., 29, 538-542.

8. Flegg, H.M. (1973): Methods of enzymatic analysis. Ann. Clin. Biochem., 10, 79.

9. Warnick, G.R., Maryfield, C.B., Benderson, J.B., Chen, J.S., and Albert, J.J. (1982): HDL cholesterol quantitation by phosphotungstate $\mathrm{Mg}^{+2}$ and by dextran sulphate $\mathrm{Mn}^{+2}$ polyethylene glycol precipitation both with enzymic cholesterol assay compared with lipid research method. Am. J. Clin. Pathol., 78, 718-722.

10. Weidal, H., and Seidal, D. (1983): A simple specific method for precipitation of low density lipoprotein. J. Lipid Res., 24, 904-909.

11. Dietary and nutritional status of populations in different states (1979): Report of the National Nutrition Monitoring Bureau, Indian Council of Medical Research, Hyderabad, India.

12. Nutrient requirements and recommended dietary allowances for Indians (1988): A report of the expert group of the Indian Council of Medical Research, Hyderabad, India.

13. Gandhi, B.M. (1982): Lipoprotein composition of normal healthy subjects in northern India. Indian J. Med. Res., 75, 393-401.

14. Mani, U.V., Goswami, S., Mani, I., Patel, S., and Gujral, S. (1986): Effect of wheat bran supplementation on serum lipids diabetic rats. Arogya J. Health Sci., 11, 168-170.

15. Chaddha, S.L., Gopinath, N., and Shekhawat, S. (1997): Urban rural differences in the prevalence of coronary heart disease and its risk factors in Delhi. Bull. WHO, 75, 31-38.

16. Kromhout, D., Bosschiter, E.B., and Coulander, C. (1985): The inverse relation between fish consumption and twenty year mortality from coronary heart disease. N. Engl. J. Med., 312, 1005-1024.

17. Schwartz, R.S. (1987): The independent effects of dietary weight loss and aerobic training on high density lipoproteins and apolipoprotein Al concentration in obese men. Metabolism, 36, 165-171.

18. Fran, Z.V., and Weltman, A. (1985): Differential effects of exercise on serum lipids and lipoprotein levels seen with changes in body weight: A meta analysis. JAMA, 254, 919-924.

19. Kiens, B., and Lewis, T. (1980): Increased plasma HDL-C and apo A1 in sedentary middle aged man after physical conditioning. Eur. J. Clin. Invest., 10, 203-209.

20. Wood, P.D., Cullinane, E.M., Esheenan, R., Sady, S.P., and Herbert, P.N. (1984): The effects of caloric restriction or exercise cessation on the lipid and lipoprotein concentration: One year randomized control study in sedentary middle aged men. Metabolism, 32, 31-39.

21. Sopako, G., Leon, A.S., and Jacobs, D.R. (1985): The effects of exercise and weight loss on plasma lipids in young obese men. Metabolism, 34, 227-236.

22. Lavie, C.J., O'Kneefe, J.H., Blonde, L., and Gau, G.T. (1990): High density lipoprotein cholesterol recommendations for routine testing and treatment. Postgrad. Med., 87, 36-45.

23. Kissebah, A.H., Vydelingum, M., Murray, R., Evans, D., Hartz, A., Kalkhoff, R., and Adams, P. (1982): Relation of body fat distribution to metabolic complication of obesity. J. Clin. Endocrinol. Metab., 54, 254-260.

24. Stern, M.P., and Haffner, S.M. (1986): Body fat distribution and hyperinsulinemia as risk factors for diabetes and cardiovascular disease. Atherosclerosis, 6, 123-130.

25. Freedman, D.S., and Rimm, A.A. (1989): The relation of body fat distribution as assessed 
by six girth measurements to diabetes mellitus in women. Am. J. Public Health, 79, 715-720.

26. Anderson, J.T., Lawler, A., and Keys, A. (1957): Weight gain from simple overeating, serum lipids and blood volume. J. Clin. Invest., 36, 81-88.

27. Peirs, A., Hennes, M., Evans, D.I., Wilson, C.R., Lee, M., and Kissebah, A.H. (1988): Relationship of anthropometric measurements of body fat distribution to the metabolic profile in pre-menopausal women. Acta Med. Scand., 723, 179-188.

28. Despres, J.P., Allard, C., Tremblay, A., Talbot, J., and Bouchard, C. (1985): Evidence for a regional component of body fatness in the association with serum lipids in men and women. Metabolism, 34, 967-973.

29. Wood, P.D., and Haskell, W.L. (1979): The effect of exercise on plasma high density lipoproteins. Lipids, 14, 417-427. 